\title{
The Effects of Acute and Chronic Haloperidol Treatment on Dopamine Release Mediated by the Medial Forebrain Bundle in the Striatum and Nucleus Accumbens
}

\author{
Michael F. Egan, M.D., Stanislaw J. Chrapusta, Ph.D., Farouk Karoum, Ph.D., \\ and Richard Jed Wyatt, M.D.
}

The delayed therapeutic effects of neuroleptics have been attributed to $\mathrm{D}_{2}$-mediated depolarization inactivation (DI) of mesolimbic dopaminergic neurons and concomitant reduction in dopamine release. Several studies have suggested, however, that DI may not reduce dopamine release and have hypothesized that this is due to increased impulse independent release. To examine the mechanisms that modulate dopamine release during $D I$, tetrodotoxin (TTX) was infused into the left medial forebrain bundle (MFB) of Sprague Dawley rats. Three-methoxytyramine (3-MT) levels 10 minutes after pargyline $(75 \mathrm{mg} / \mathrm{kg}$ ) were used as a measure of dopamine release. A dose response study showed that infusions of $10^{-5} \mathrm{~mol} / \mathrm{L}$ and $10^{-4} \mathrm{~mol} / \mathrm{L}$ TTX reduced 3-MT levels on the infused side by $70 \%$ in the striatum and $50 \%$ to $60 \%$ in the nucleus accumbens. In a time course study, $10^{-5} \mathrm{~mol} / \mathrm{L}$ TTX reduced striatal 3-MT at 30,90 , and 120 minutes.
After intraperitoneal injections of haloperidol $(0.4 \mathrm{mg})$ $\mathrm{kg}$ ) for 1 or 21 days, TTX infusions again reduced 3-MT levels by approximately $70 \%$ in the striatum and $53 \%$ to $59 \%$ in the nucleus accumbens on the infused side. Acute and chronic haloperidol treatment did not alter the percent of TTX-induced reductions. These data suggest that dopaminergic neuronal impulse flow modulates similar amounts of total transmitter release after both acute and chronic haloperidol treatment. The results do not support the notion that DI mediates the antipsychotic effects of neuroleptics by markedly reducing total basal dopamine release or increasing impulse independent release. Alternatively, DI could reduce psychotic symptoms by changing the responsiveness of the dopamine system to external stimuli or by reducing synaptic dopamine levels that have been hypothesized to be elevated in psychotic patients. [Neuropsychopharmacology 14:211-223, 1996]
KEY WORDS: Depolarization inactivation; Haloperidol; Neuroleptic; Dopamine; 3-Methoxytyramine; Nigrostriatal; Mesolimbic; Psychosis

From the Neuropsychiatry Branch, National Institute of Mental Health Neuroscience Research Center at St. Elizabeth, 2700 Martin Luther King Jr. Avenue, S.E., Washington, DC 20032.

Address correspondence to: Michael F. Egan, M.D., Neuropsychiatry Branch, National Institute of Mental Health, Neuroscience Research Center at St. Elizabeth, 2700 Martin Luther King Jr. Ave., S.E. Washington, DC 20032.

Received May 26, 1993; revised March 14, 1995; accepted May 23 1995.
Antipsychotic medications are thought to exert their therapeutic effects through dopamine $D_{2}$ receptor blockade. This hypothesis is supported by the strong correlation between the clinical potency of neuroleptics and their affinity for dopamine $D_{2}$ receptors (Creese et al. 1976). One difficulty with this hypothesis is the delay in therapeutic efficacy of neuroleptics. Whereas blockade of dopamine $D_{2}$ receptor blockade occurs within several hours, antipsychotic effects take several days or weeks to develop (Glovinski et al. 1992; Carr 1983; Keck et al. 1989; however, see Stern et al. 1993). 
Time-dependent changes in the dopamine system have been invoked to explain the delay in therapeutic efficacy of antipsychotic drugs. Several investigators (White and Wang 1983a,b; Chiodo and Bunney 1983, 1985) have demonstrated that most dopamine neurons become electrically inactive during 2 to 3 weeks of drug treatment. This phenomenon, described as depolarization inactivation (DI), has been produced by a variety of neuroleptics, doses, routes of administration, and lengths of treatment (Bunney and Grace 1978; White and Wang 1983a,b; Chiodo and Bunney 1983, 1985, 1987; Scarsfeldt 1988). DI's antipsychotic effects were hypothesized to result from marked reductions in impulse-dependent dopamine release, with limited residual levels becoming impulse independent (Chiodo and Bunney 1983, 1985). Acute neuroleptic treatment, on the other hand, markedly increases dopamine firing rates and release (Zetterstrom et al. 1985; Imperato and Di Chiara 1985). This initial increase has been hypothesized to acutely overcome the blockade of dopamine $\mathrm{D}_{2}$ receptors (Chiodo and Bunney 1983, 1985; Blaha and Lane 1987; Grace 1991). If DI produces a gradual reduction in dopamine release over several days or weeks, the net stimulation of postsynaptic $D_{1}$ and $D_{2}$ dopamine receptors would also gradually decrease, leading to an improvement in psychotic symptoms (Chiodo and Bunney 1985; Blaha and Lane 1987).

Several methods have been used to examine extracellular dopamine levels during long-term antipsychotic treatment. Results from in vivo microdialysis studies have conflicted. Some have found reductions (Bettini et al. 1987; Ichikawa and Meltzer 1990; Chen et al. 1991), whereas others have reported no change or persistent elevations in dopamine levels (Gonon 1988; Invernizzi et al. 1990; Zhang et al. 1989; Hernandez and Hoebel 1989; See et al. 1992; Moghaddam and Bunney 1993). Possible explanations for these discrepancies include differences in use of anesthesia (Zhang et al. 1989), types of perfusates (Tepper et al. 1991), variability in basal measures, or placement of probes. Furthermore, insertion of the dialysis probe itself could produce sufficient tissue disruption to reverse DI (Grace 1992). Using in vivo voltammetry, Lane and Blaha (1987) reported reduced dopamine signal, supporting the DI hypothesis. On the other hand, Compton and Johnson (1989) used in vitro slices and electrical field stimulation and did not find lower extracellular dopamine in either the striatum or nucleus accumbens. These studies, although inconsistent, raise serious questions about the association of DI and reduced dopamine release (Grace 1991).

Three-methoxytyramine (3-MT) accumulation after pargyline administration has been shown to be a good index of dopamine release (Wood and Altar 1988). Assaying 3-MT accumulation does not require in vivo tissue disruption, and thus has a potential advantage when studying DI. Dialyzable 3-MT levels are highly correlated with, and reflect changes in, dialyzable dopamine under many conditions (Wood et al. 1987, 1988), including after pargyline (Butcher et al. 1990) and acute antipsychotic treatment (Brown et al. 1991). It has been suggested that 3-MT levels may reflect receptor-relevant dopamine concentrations more accurately than extracellular dopamine (Kuczenski and Segal 1992). Extracellular 3-MT has the same fractional rate constant as tissue 3-MT, indicating that these are essentially identical pools (Wood et al. 1988). Tissue 3-MT accumulation, in particular, is a dynamic measure of dopamine release that appears more sensitive, under a number of conditions, than steady-state 3-MT levels for assessing changes in dopamine release (Karoum and Egan 1992; Karoum et al. 1994a,b). 3-MT accumulation is elevated in the striatum and nucleus accumbens after chronic treatment with antipsychotic medications (Egan et al. 1991), adding support to those studies suggesting that antipsychotics do not reduce synaptic dopamine during DI [for review, see Grace (1991)].

It is unclear what processes regulate dopamine release during DI. One possibility is that increased impulseindependent transmitter release compensates for reduced impulse flow (Grace 1991, 1992; Hollerman et al. 1992). In this case, cortical glutamatergic projections might regulate dopamine release. A second possibility is that residual dopamine neuronal impulse flow continues to regulate dopamine release. Dopamine neuronal firing can be blocked with gamma-butyrolactone (GBL). Treatment with GBL after long-term neuroleptic administration produces a marked reduction in striatal and nucleus accumbens' 3-MT accumulation (Chrapusta et al. 1994), suggesting impulse flow modulates release during DI. It is unclear, however, whether GBL could affect impulse-independent dopamine release, such as that which could be mediated by glutamate.

A second method used to block dopamine neuronal impulse flow may be more specific. Tetrodotoxin (TTX) is a neurotoxin that blocks voltage-gated sodium channels (Narahashi 1974). Infusion of TTX into the medial forebrain bundle (MFB) has been shown to block nigrostriatal neuronal impulse flow (Commissiong et al. 1990) and to reduce extracellular dopamine in the striatum. This effect is not due to reduced glutamate neurotransmission (Keefe et al. 1992), and thus is most likely due to blockade of dopaminergic neuronal impulse flow. TTX infusions into the MFB during long-term neuroleptic treatment should block any residual dopaminergic neuronal impulse flow. Marked reductions in dopamine release after TTX infusions would indicate that the MFB continues to mediate significant portions of dopamine release (Egan et al. 1993). The goal of this study was to examine the effects of acute and chronic neuroleptic treatment on the amount of dopamine release controlled by impulse flow through the MFB, using TTX infusions to block this impulse flow. 


\section{METHODS}

Male Sprague-Dawley rats (Zivic Miller, Allison Park, PA) weighing between 350 and $410 \mathrm{~g}$ at time of infusions were used for all experiments. Animals were housed three per cage and maintained on a 12-hour light/dark cycle (light 7 A.M. to 7 P.M.) with free access to food and water. Deep anesthesia was obtained using a mixture of ketamine $(70 \mathrm{mg} / \mathrm{kg})$ and xylazine $(6 \mathrm{mg} / \mathrm{kg})$ injected intraperitoneally (IP) 30 minutes prior to surgery. Tetrodotoxin (TTX) (Sigma Chemical Co., St. Louis, MO) or an equal volume of vehicle (saline buffered with $1 \mathrm{mM}$ phosphate, $\mathrm{pH}$ 7.4) was infused into the left MFB through a 28-gauge stainless steel cannula connected to a $10 \mu \mathrm{l}$ Hamilton syringe. Infusion rate and time $(1 \mu \mathrm{l} /$ min for 1.5 minutes) were controlled using a Harvard syringe infusion pump (\#22, Harvard Apparatus, Southnatick, MA). Cannulae were slowly lowered into the brain to the following coordinates: $\mathrm{AP}-2.6 \mathrm{~mm}$, ML
$+2.0 \mathrm{~mm}$, and DV $-8.4 \mathrm{~mm}$ relative to bregma (Paxinos and Watson 1986). After infusion, cannulae remained in place for 5 minutes and then were slowly withdrawn. Flow of infusate was immediately assessed by visual inspection for 10 to 20 seconds. In no case was the flow blocked or noticeably slowed. Test injections of $1 \%$ methylene blue dye followed by decapitation and cutting the brain in $0.2-\mathrm{mm}$ sections indicated that cannulae reproducibly $(n=5)$ infused dye into an area incorporating the left MFB (Figure 1A-F). In some brains, small amounts of staining were seen in the caudal striatum (1D), which was not included in dissections of the striatum. In all experiments, cannula tracks were visually verified to be posterior to the striatum, through the hippocampus, and roughly at the same depth as the dorsal tip of the third ventricle.

In the first experiment, the effects of dose on striatal and nucleus accumbens' $3-\mathrm{MT}$ accumulation were examined using three concentrations of TTX $\left(10^{-6} \mathrm{~mol} / \mathrm{L}\right.$, a

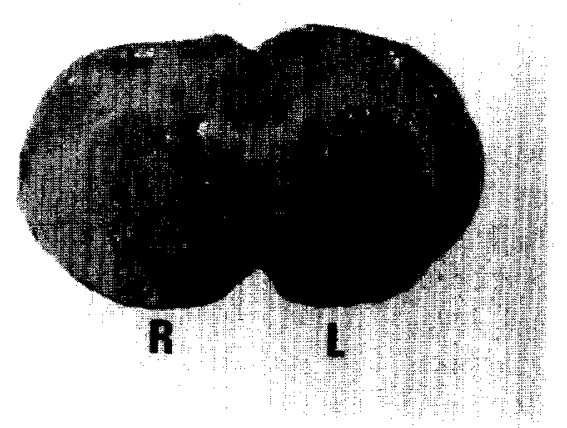

b

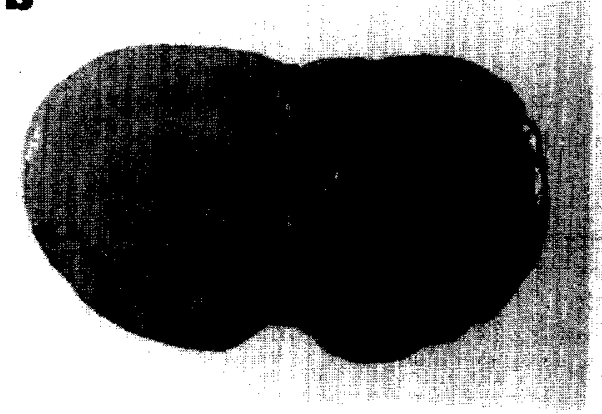

C

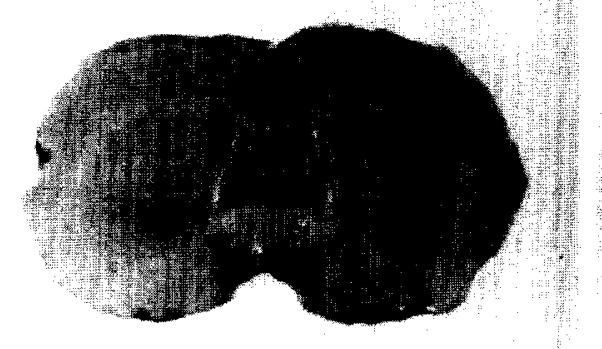

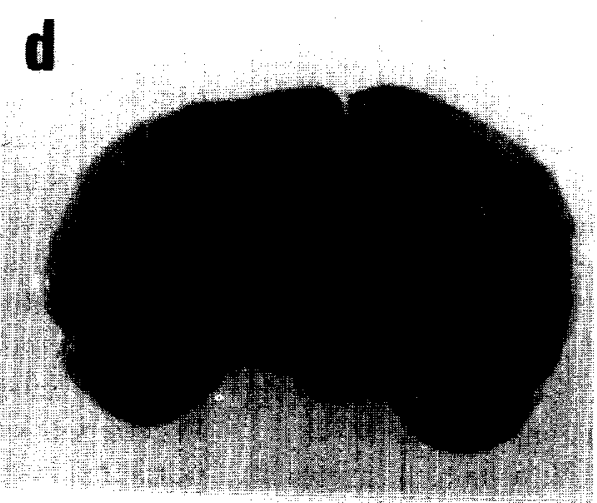
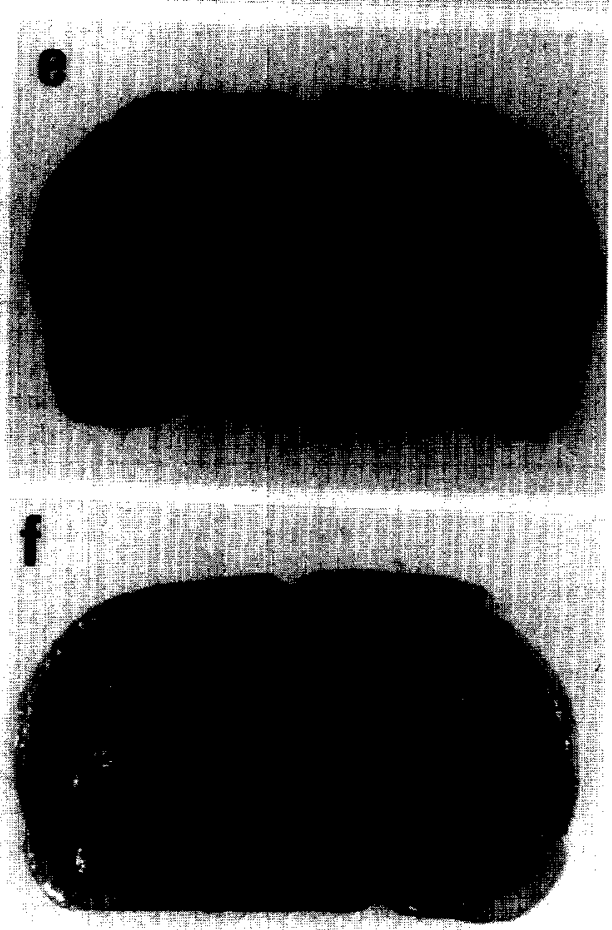

Figure 1. Photographs of dye infusions into the left MFB (right side of pictures) in unstained rat brain (all coordinates are approximate and given in $\mathrm{mm}$ relative to bregma in the anterior-posterior dimension). (a) the striatum is unstained at +1.70 , (b) +1.20 , and (c) +.3 to +.5 ; in (d) at -2.10 , there is slight staining of the most ventral and caudal portion of the striatum (not included in dissections); (e) at approximately -2.3 , the cannula track is seen entering the cortex while a region incorporating the MFB is stained; (f) -2.6 with the lower portion of the cannula track apparent and clear staining of a region incorporating the MFB. 
$10^{-5} \mathrm{~mol} / \mathrm{L}$, or $10^{-4} \mathrm{~mol} / \mathrm{L}$ ) or vehicle $(n=4$ per group) infused 30 minutes before death by microwave irradiation. In the second study, time effects were assessed using a $10^{-5} \mathrm{~mol} / \mathrm{L}$ TTX solution infused at 30 minutes, 90 minutes, and 120 minutes prior to death. Separate control groups were infused at each time point with an equal volume of vehicle. 3-MT accumulation was measured in the striatum only.

To assess the effects of TTX infusion on 3-MT accumulation after chronic haloperidol treatment, animals were injected IP with either haloperidol $(0.4 \mathrm{mg} / \mathrm{kg})$ (McNeil Pharmaceuticals, Spring House, PA) or an equal volume of vehicle for 3 weeks. Haloperidol was dissolved in $0.1 \mathrm{ml}$ glacial acetic acid, diluted with distilled water, and adjusted to approximately $\mathrm{pH} 5.6$ with $\mathrm{NaOH}$. On the 21st day, animals were given a final IP injection 1 hour before death. Vehicle or TTX solutions were infused into the left MFB, 30 minutes prior to death. Animals treated chronically with vehicle (vehchronic; see Table 1) received a final IP injection of either vehicle (veh chronic $_{\text {/veh }}$ acute group) or haloperidol (vehchronic/haloperidolacute group) followed by TTX or vehicle infusion. Rats treated chronically with haloperidol (haloperidol chronic $_{\text {) }}$ were also given a final injection 1 hour before being killed of either haloperidol (haloperi-

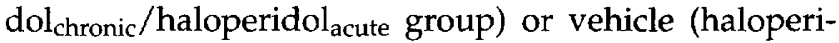
$\mathrm{dol}_{\text {chronic }} / \mathrm{veh}_{\text {acute }}$ group). The latter group was used as a baseline to assess the acute effects of the last of 21 daily injections of haloperidol. The haloperidol chronic $_{\text {/ }}$ haloperidol ${ }_{\text {acute }}$ and haloperidol ${ }_{\text {chronic }} / \mathrm{veh}_{\text {acute }}$ groups were then divided into two groups each, one receiving vehicle and the second, TTX infusions into the MFB.

Three-methoxytyramine was allowed to accumulate for 10 minutes after pargyline hydrochloride adminis- tration $(75 \mathrm{mg} / \mathrm{kg}, \mathrm{IP})$ as previously described (Egan et al. 1991). Animals were then killed by focused beam microwave brain irradiation $(2450 \mathrm{MHz}, 7 \mathrm{~kW}$ for $1.3 \mathrm{sec}-$ onds) (Radio Japan NJE 2603, Great Plains Laboratories, Norman, OK) which prevents postmortem alterations in 3-MT concentrations [for review, see Wood and Altar (1988)]. After decapitation, brains were removed and placed on ice. Right and left striata and nuclei accumbens were dissected and analyzed separately. The caudalmost portions of the striatum [approximately -2.3 to $-3.8 \mathrm{~mm}$ from bregma (Paxinos and Watson 1986)] were not included. The hypothalamus was also dissected for the veh chronic $_{\text {/veh }}$ acute groups followed by either TTX or vehicle infusion. A model 4500 Finnigan gas chromatographic/quadrupole mass spectrometer was used to assess 3-MT, as previously described (Karoum and Egan 1992).

Three-methoxytyramine levels were analyzed using a repeated measures multivariate analysis of variance (MANOVA). Each experiment included within (side of brain) and between (dose, time, infusion [TTX versus vehicle] or drug treatment [acute and chronic vehicle or haloperidol]) factors. For clarity, only relevant and significant interactions (of within and between factors) are reported later. The Contrast function (or paired $t$ tests when specified) on SuperANOVA (Abacus Concepts, Berkeley, CA) was used for comparisons of specific groups and sides. To examine the effects of TTX infusions in individual groups, levels on the TTX-infused left side were compared with those on the right side as well as left-sided levels in vehicle-infused animals. Where both comparisons are significant, left/right comparisons are presented. Effects of haloperidol treatment alone were examined using only vehicle-infused groups.

Table 1. Treatment of Groups Used to Assess the Effects of TTX Infusions into the MFB on 3-MT Levels During Deoplarization Inactivation Induced by Repeated Haloperidol Administration

\begin{tabular}{|c|c|c|c|}
\hline \multirow[b]{2}{*}{ Group } & \multicolumn{3}{|c|}{ Treatment } \\
\hline & $\begin{array}{c}\text { Chronic } \\
\text { (20 daily } \\
\text { injections) }\end{array}$ & $\begin{array}{c}\text { Acute } \\
\text { (1 hour before } \\
\text { death) }\end{array}$ & $\begin{array}{c}\text { Infusion } \\
\text { (into the MFB) }\end{array}$ \\
\hline veh $_{\text {chronic }} /$ veh $_{\text {acute }}$ & $\begin{array}{l}\text { Vehicle } \\
\text { Vehicle }\end{array}$ & $\begin{array}{l}\text { Vehicle } \\
\text { Vehicle }\end{array}$ & $\begin{array}{l}\text { Sham } \\
\text { TTX }\end{array}$ \\
\hline veh $_{\text {chronic }} /$ haloperidol acute & $\begin{array}{l}\text { Vehicle } \\
\text { Vehicle }\end{array}$ & $\begin{array}{l}\text { Haloperidol } \\
\text { Haloperidol }\end{array}$ & $\begin{array}{l}\text { Sham } \\
\text { TTX }\end{array}$ \\
\hline haloperidol chronic $_{\text {/veh }}$ acute & $\begin{array}{l}\text { Haloperidol } \\
\text { Haloperidol }\end{array}$ & $\begin{array}{l}\text { Vehicle } \\
\text { Vehicle }\end{array}$ & $\begin{array}{l}\text { Sham } \\
\text { TTX }\end{array}$ \\
\hline haloperidol $_{\text {chronic }} /$ haloperidol acute & $\begin{array}{l}\text { Haloperidol } \\
\text { Haloperidol }\end{array}$ & $\begin{array}{l}\text { Haloperidol } \\
\text { Haloperidol }\end{array}$ & $\begin{array}{l}\text { Sham } \\
\text { TTX }\end{array}$ \\
\hline
\end{tabular}

Abbreviations are based on the treatments they received (in order): (1) chronic-20 daily injections of vehicle or haloperidol; (2) acute-injections of vehicle or haloperidol 1 hour before death. Each group was further divided into two seperate groups and infused with either TTX or vehicle (sham) into the MFB 30 minutes before death. 
To look for evidence of DI-induced alterations in impulse flow, residual 3-MT levels on the left (infused) sides in TTX-infused groups were compared in groups treated acutely versus those treated chronically with haloperidol (i.e., veh $_{\text {chronic }} /$ haloperidol $_{\text {acute }}$ versus haloperidol $_{\text {chronic }} /$ haloperidol $_{\text {acute }}$ groups).

\section{RESULTS}

\section{Dose/Response and Time Course Studies}

In the dose/response study, the two higher TTX doses markedly reduced 3-MT accumulation in the striatum and nucleus accumbens (see Figures $2 \mathbf{A}$ and $\mathbf{B}$ ). In both

\section{Striatal Dose Response}

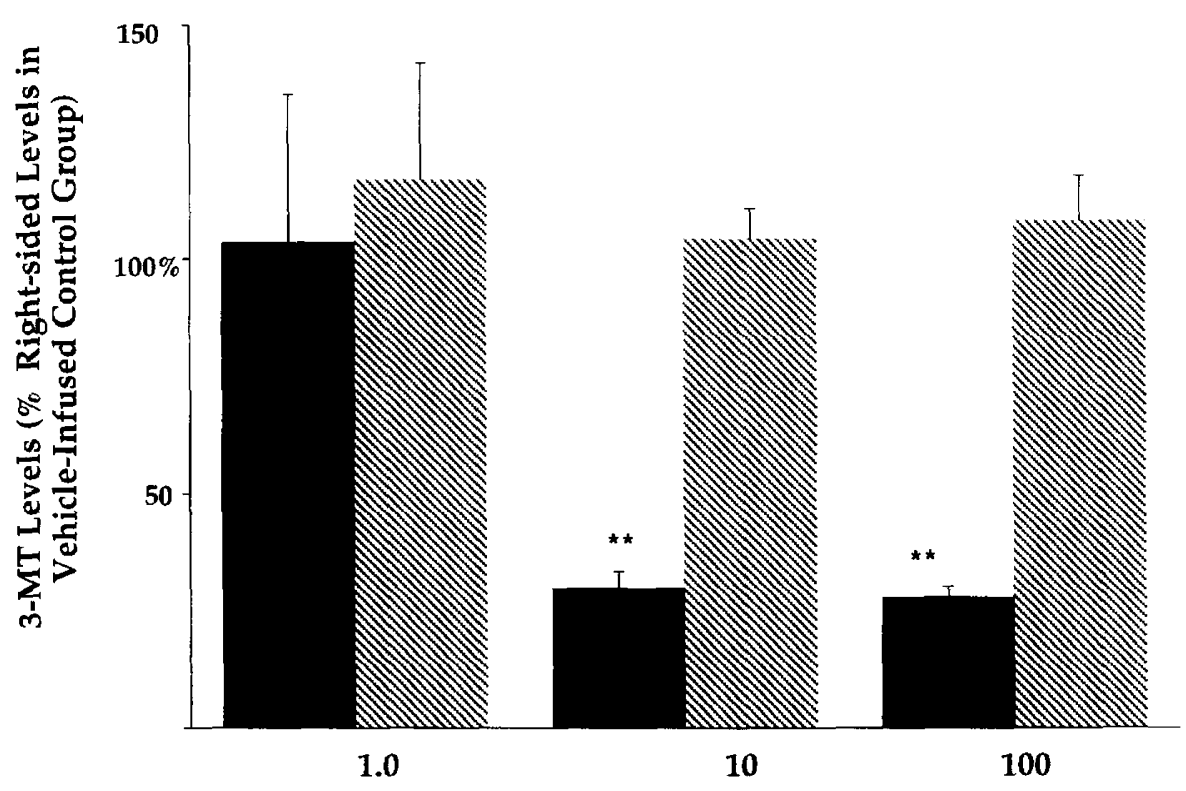

A

\section{TTX Concentration (uM)}

\section{Nucleus Accumbens' Dose Response}

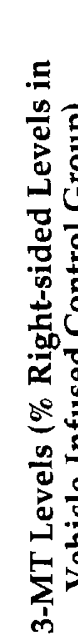

150
$100 \%$
50

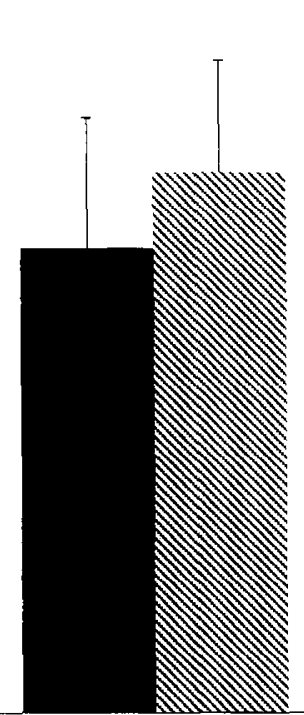

$\mathbf{1 . 0}$

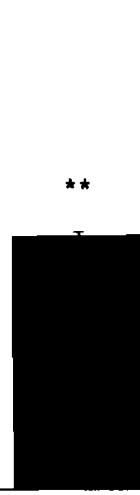

10

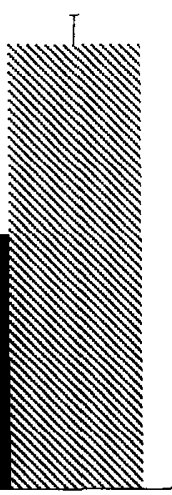

10

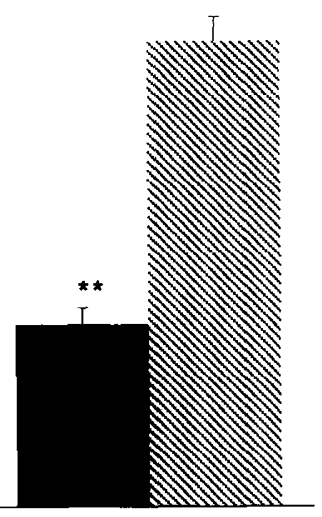

100
Figure 2. (A) Striatal dose response: TTX infusions into the left MFB significantly lower 3-MT levels on the left compared with those on the right at the higher two doses $(F=8.04, d f=3, p=$ .003). (B) Nucleus accumbens dose response: TTX infusions into the left MFB significantly lower 3-MT levels on the left compared with those on the right at the higher two doses $(F=12.8$, $d f=3, p=.0005$ ). 3-MT accumulation $( \pm S E)$ is expressed as a percentage of the mean of levels on the right (noninfused side) in the control group (not shown). Levels on the left (infused) side in TTX infused animals are contrasted with those on the right for all post hoc comparisons. ( $n=4$ per group;

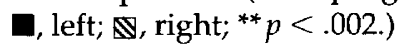


Figure 3. Striatal time course: 3MT levels are significantly reduced at all time points on the left side compared with the right after TTX infusions into the left MFB ( $F=$ $7.6, d f=1, p=.01)$. 3-MT accumulation $( \pm \mathrm{SE})$ is expressed as a percentage of the mean of all rightsided levels in the vehicle control groups (one for each time, data not shown). Left-sided levels in TTX infused animals are contrasted with those on the right side for post hoc comparisons. ( $n=3$ to 5

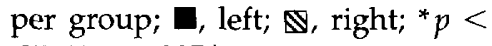
$.05 ;{ }^{* *} p<.005$.)

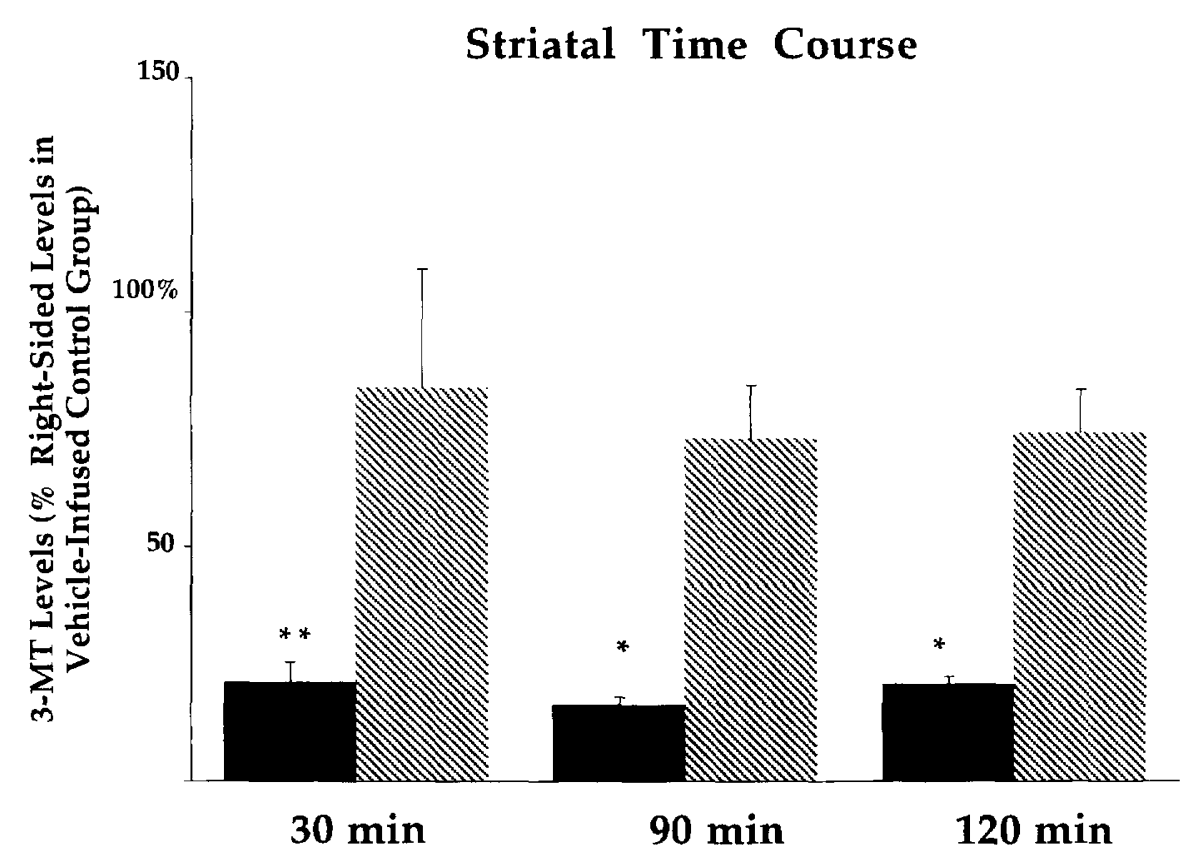

the $10^{-5} \mathrm{~mol} / \mathrm{L}$ and $10^{-4} \mathrm{~mol} / \mathrm{L}$ TTX-infused groups compared with those on the noninfused (right) side. Vehicle infusions did not alter levels in any brain region (infused versus noninfused sides).

The results of the time course study are shown in
Figure 4. Striatal 3-MT levels after TTX infusions into the left MFB: The effects of vehicle or haloperidol treatment combined with TTX MFB infusions on striatal 3-MT levels (ng/mg protein) ( $\pm \mathrm{SE}$ ) 10 minutes after pargyline. Acute ( 1 hour before killing) and chronic (20 daily injections) treatments are listed on the $x$ axis. Significant effects were seen for infusion (vehicle versus TTX) $(F=$ 15.3, $d f=1, p=.0003$ ) and side (left versus right) $(F=109.3, d f=$ $1, p=.0001)$. Significant interactions were seen for infusion by side $(F=42.5, d f=1, p=.0001)$, and treatment (vehicle versus haloperidol) by infusion by side $(F=4.72, d f=3, p=.006)$. Leftsided levels in TTX-infused animals are contrasted with those on the right for all post hoc comparisons $(F=5.45$ to $88.9 ; d f=1$, $p=.02$ to .0001 ). Assuming inadequate TTX perfusion, one animal with higher levels on the left than right was excluded in the TTX-infused vehicle group $(n=5$ to 8 per group; $\mathbf{\square}$, left, $\mathbb{\mathbb { N }}$, right; ${ }^{*} p<.02 ;{ }^{* *} p<.0001$.)

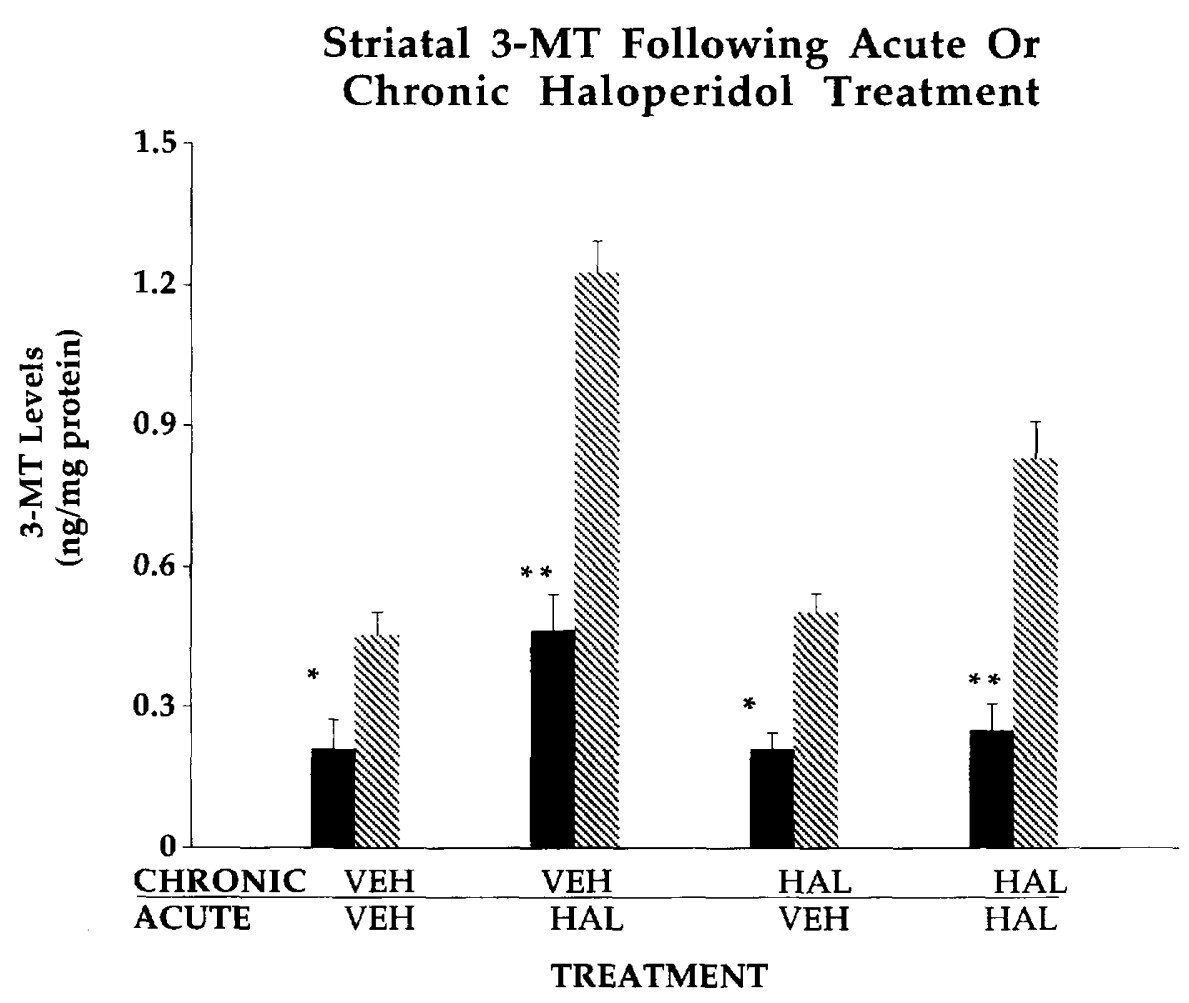


Figure 3. In the striatum, $10^{-5} \mathrm{~mol} / \mathrm{L}$ TTX lowered 3-MT levels on the infused (left) side at all time points by $74 \%$ to $80 \%$ compared with those on the noninfused (right) side. Vehicle infusion again had no effect.

\section{Effects of MFB Infusions During Chronic Haloperidol Administration}

Haloperidol Effect. The effects of haloperidol treatment alone were the same as those previously described (Egan et al. 1991). In both the striatum and nucleus accumbens, an acute haloperidol injection after either chronic vehicle or chronic haloperidol (veh chronic $_{\text {halo- }}$ peridol $_{\text {acute }}$ or haloperidol chronic $_{\text {/ }}$ haloperidol acute groups) increased 3-MT levels above those in appropriate control groups (i.e., $v h_{\text {chronic }} /$ veh $_{\text {acute, }}$ or haloperidol ${ }_{\text {chronic }} /$ veh $_{\text {acute }}$ groups respectively) $(F=24.7, d f=3, p=.0001$ and $F=18.2$, df $=3, p=.0001$ for the two regions, respectively).

TTX Effect. In animals receiving TTX infusions, levels on the left were significantly lower than those on the right (paired $t$ test, $t=7.71, p=.0001 ; t=6.9, p=.0001$, in the striatum and accumbens, respectively) (see Figures 4 and 5). TTX infusions also lowered 3-MT levels on the infused side compared to levels in vehicle infused animals in the striatum and nucleus accumbens respectively (striatum: infusion effect, $F=15.3, d f=1, p=$ .0003 ; side-effect, $F=109.3, d f=1, p=.0001$; infusion by side interaction, $F=42.5, d f=1, p=.0001$; accumbens: infusion effect, $F=5.55, d f=1, p=.02$; sideeffect, $F=83.2, d f=1, p=.0001$; infusion by side interaction, $F 30.4, d f=1, p=.0001$ ). Vehicle infusions also lowered levels slightly on the left side (by $12 \%$ ) compared to those on the right in both regions (paired $t$ test, $t=4.28, p=.0002, t=3.63, p=.001$ for striatum and accumbens, respectively).

Acute Versus Chronic Haloperidol. The effects of haloperidol treatment combined with TTX infusions on striatal 3-MT levels are displayed in Figure 4. In the group treated acutely with haloperidol $\left(\mathrm{veh}_{\text {chronic }} /\right.$ haloperidol $_{\text {acute }}$ group), TTX infusions reduced 3-MT levels on the infused compared with the noninfused side by $70 \%$ $(F=22.0, d f=1, p<.0001)$. TTX infusion produced a similar $60 \%$ to $70 \%$ reduction in striatal $3-\mathrm{MT}$ on the infused compared with the noninfused side in both groups treated chronically with haloperidol (haloperi$\mathrm{dol}_{\text {chronic }} / \mathrm{haloperidol}_{\text {acute }}$ and haloperidol $\mathrm{c}_{\text {chronic }} / \mathrm{veh}_{\text {acute }}$ ) $(F=24.4, d f=1, p=.0001 ; F=9.16, d f=1, p=.004$, respectively). No differences were seen in percent of TTX-induced reductions comparing the veh $\mathrm{chronic}_{\text {/ halo- }}$ peridol $_{\text {acute }}$ group with the haloperidol chronic $_{\text {/haloperi- }}$

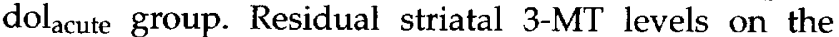

\section{Nucleus Accumbens' 3-MT Following Acute Or Chronic Haloperidol Treatment}

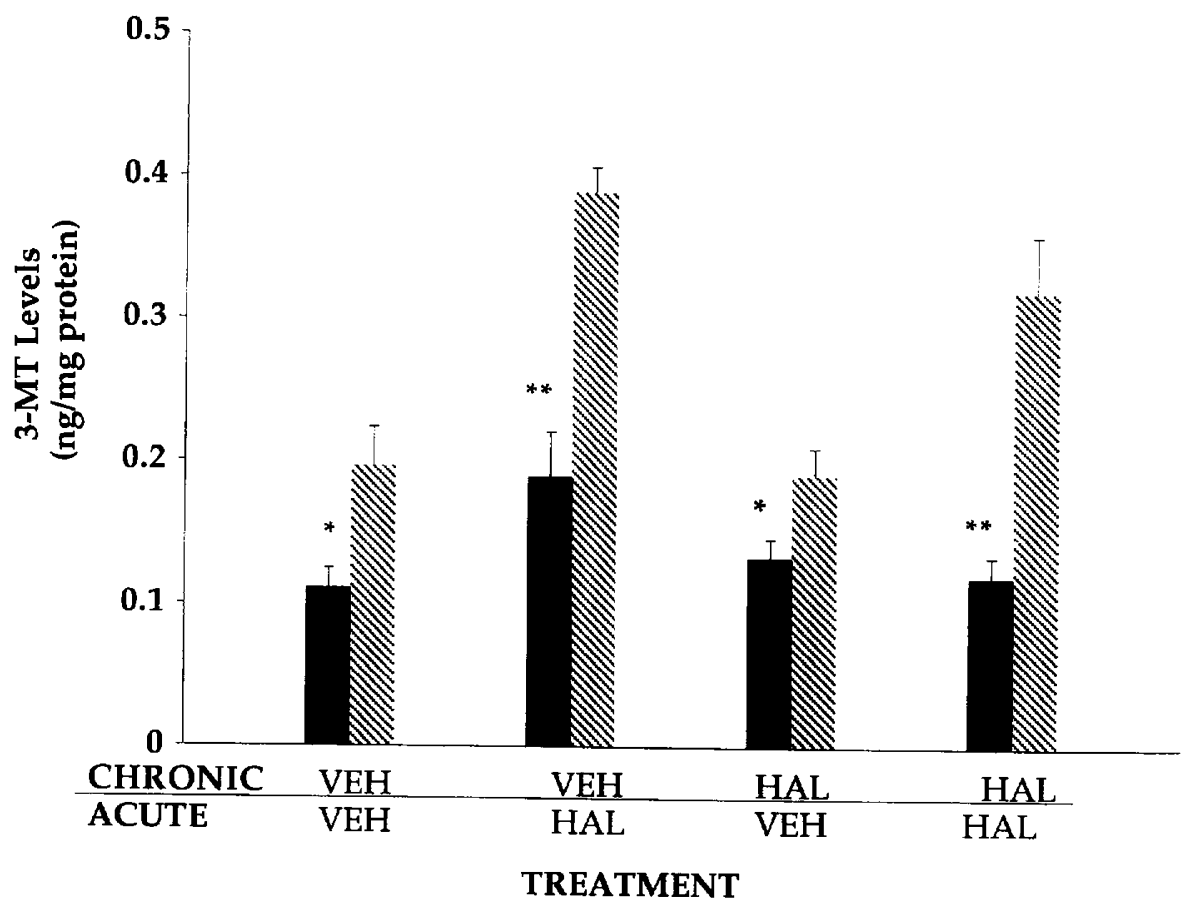

Figure 5. Nucleus accumbens' 3-MT levels after TTX infusions into the left MFB: The effects of vehicle or haloperidol treatment combined with TTX MFB infusions on 3-MT levels (ng/mg protein) ( $\pm \mathrm{SE}$ ) 10 minutes after pargyline in the nucleus accumbens. Acute ( 1 hour before killing) and chronic (20 daily injections) treatments are listed on the $x$ axis. Significant effects were seen for infusion (vehicle versus TTX) $(F=5.55, d f=1, p=$ $.02)$ and side (left versus right) $(F=83.2, d f=1, p=.0001)$. Interactions were seen for infusion by side $(F=30.4, d f=1, p=$ .0001 ), and drug treatment (vehicle versus haloperidol) by infusion by side $(F=5.52, d f=3, p=$ .0025). Left-sided levels in TTX infused animals are contrasted with those on the right for all post hoc comparisons $(F=5.45$ to $60.0, d f=1, p=.04$ to .0001$)(n=6$ to 8 per group; $\square$, left; $\$$, right; ${ }^{*} p<.02 ;{ }^{* *} p<.0001$.) 
infused side in the haloperidol chronic $_{\text {/haloperidol }}$ acute group tended to be lower than levels in the veh chronic/ haloperidol acute group $(F=3.3, d f=1, p<.08)$.

The effects of TTX infusions on 3-MT levels in the nucleus accumbens are displayed in Figure 5. TTX infusions reduced nucleus accumbens' 3-MT in the infused (left) side of the acute haloperidol group ( veh $_{\text {chronic }}$ ) haloperidol acute) by $52 \%$ compared with levels on the noninfused (right) side $(F=23.5, d f=1, p<.0001)$. TTX infusion produced a similar 59\% reduction in striatal 3-MT on the infused (left) side in the chronically treated group (haloperidol chronic $_{\text {/haloperidol }}$ acute $)(F=10.5$, $d f=1, p<.002$ ). No differences were seen in percent of TTX-induced reductions comparing veh $\mathrm{v}_{\text {chronic }} /$ haloperidol $_{\text {acute }}$ and haloperidol ${ }_{\text {chronic }} /$ haloperidol $_{\text {acute }}$ groups. Residual 3-MT levels on the infused (left) side in the haloperidol $_{\text {chronic }} /$ haloperidol $_{\text {acute }}$ group were lower than levels in the veh chronic $_{\text {/haloperidol acute }}$ group $(F=$ $3.9, d f=1, p=.05$ ).

The capacity of TTX infusion to reduce 3-MT in the striatum was compared with that in the nucleus accumbens using all TTX-infused groups in Table 1. Reductions in the striatum were significantly lower than those in the nucleus accumbens $(t=3.71, d f=26, p=.001)$.

\section{DISCUSSION}

The results of the dose response and time course experiments demonstrate that TTX infusions into the MFB consistently reduced 3-MT accumulation in nigrostriatal and mesolimbic projection areas of dopamine neurons. Striatal 3-MT levels were markedly reduced 30, 90, and 120 minutes after infusion using a $10^{-5} \mathrm{~mol} / \mathrm{L}$ solution. Similar reductions were seen in the nucleus accumbens. These data indicate that MFB TTX infusions block nigrostriatal and mesolimbic dopaminergic neuronal impulse flow.

Because robust effects were found in the striatum and nucleus accumbens for the $10^{-5} \mathrm{~mol} / \mathrm{L}$ TTX infusions after 30 minutes, this time and dose combination was selected for the chronic haloperidol experiment. The lower effective dose and short time interval were chosen for further studies to limit possible effects from diffusion to neighboring regions.

TTX infusions into the MFB following both acute and chronic haloperidol treatment reduced striatal 3-MT accumulation by $63 \%$ and $70 \%$, respectively. Similarly, in the nucleus accumbens, TTX infusions reduced 3-MT accumulation after both acute and chronic haloperidol by $52 \%$ and $59 \%$, respectively. In both regions, chronic haloperidol treatment did not significantly alter the amount of dopamine release related to neuronal impulse flow in the MFB. Overall, the results suggest that chronic neuroleptic treatment and DI neither reduce dopamine release nor alter the amount of release dependent on impulse flow through the MFB.

The mean TTX-induced reduction in 3-MT accumulation after both acute and chronic haloperidol appear to be less than that found after systemic GBL treatment (Chrapusta et al. 1994) in the striatum (67\% versus $89 \%$ ) as well as the nucleus accumbens ( $55 \%$ versus $75 \%$ ). The difference may be due to innervation from the contralateral dopaminergic cell bodies, which would be blocked with systemic GBL but not unilateral TTX MFB infusions. Whereas one study in neonatal and juvenile rats found only $1 \%$ to $2 \%$ cross-innervation (Alter et al. 1983 ), a second study in the adult rat reported that $5 \%$ to $10 \%$ of nigrostriatal innervation comes from the contralateral side (Loughlin and Fallon 1982). Contralateral projections could compensate to some degree for the decrease in dopamine release in ipsilateral dopamine neurons. To test this hypothesis, 3-MT accumulation after bilateral MFB TTX infusions was compared to levels in an anesthetized, noninfused control group. Bilateral infusions reduced 3-MT accumulation by $86 \%$ in the striatum and $73 \%$ in the nucleus accumbens. This is virtually identical to reductions after systemic GBL injections of $89 \%$ and $75 \%$, in the respective regions (Chrapusta et al. 1992). Contralateral dopaminergic innervation may also account for the trend of haloperidol to elevate 3-MT levels relative to vehicle-treated controls on TTX infused sides.

Reductions in nucleus accumbens' 3-MT levels after TTX infusions or GBL appear to be less than those seen in the striatum. Differences between the striatum and nucleus accumbens could be due to a variety of factors, such as differences in sensitivity of nigral and VTA neurons to TTX infusions and GBL, or higher relative contribution from impulse flow-independent dopamine release in the nucleus accumbens (Chrapusta et al. 1992). Alternatively, the difference may simply reflect regional differences in 3-MT metabolism. In the accumbens, a smaller fraction of released dopamine appears to be metabolized to 3-MT, relative to the striatum (Kuczenski and Segal 1992). This suggests that residual 3-MT levels may make up a larger percentage of basal 3-MT levels. Furthermore, it is unclear what the low residual levels of 3-MT (or, with dialysis, residual extracellular dopamine) actually reflect. Whereas TTX independence has been assumed to indicate release that is not dependent on impulse flow, these low levels of residual 3-MT (and dopamine) could also represent sequestered pools that are resistant to further metabolism.

Previous studies assessing impulse dependent versus independent release have produced somewhat conflicting results. Most relevant studies have infused TTX directly into the striatum, measured dialyzable dopamine, and assumed that residual dopamine levels reflect impulse independent release (Westerink and De Vries 1988). Osborne et al. (1990), for example, found that the 
TTX-induced reduction in basal dopamine levels varied from $58 \%$ to $85 \%$ from 1 to 4 days after probe implantation. Westerink and De Vries (1988), on the other hand, reported that extracellular dopamine during TTX perfusion was undetectable 1 day after probe implantation. One difficulty using dialysis to assess impulse independent release is that the latter is increased by probe insertion. This is most likely due to the resulting tissue damage and denervation of dopamine terminals. Delays of 24 to 96 hours have been used to reduce the impact of this leakage (Osborne et al. 1990). Recent dialysis studies have reported that 24 hours after probe implantation, residual, TTX-resistant dialyzable dopamine levels range from $0 \%$ to $42 \%$ of basal values (average approximately $17 \%$ ) (e.g., see Westerink and De Vries 1988; Osborne et al. 1990; Kalivas and Duffy 1991; Cenci et al. 1992; Tanaka et al. 1992; Schmidt et al. 1994). Whereas dopamine "leakage" is reduced over time, it is unclear how local tissue damage and subsequent edema affect dopamine release, uptake, extracellular metabolism, and residual levels following TTX.

A smaller group of studies have assessed impulse independent release after unilateral TTX infusion into the MFB. These reports generally find dialyzable dopamine levels below the limits of detection 60 to $90 \mathrm{~min}-$ utes after perfusion of TTX (Moghaddam and Bunney 1993; Keefe et al. 1992, 1993; although, see Miu et al. 1992). It seems very unlikely, however, that these unilateral infusions would reduce synaptic dopamine to zero. As reviewed earlier, studies with direct TTX infusion into the striatum after probe implantation suggest that a significant amount of dopamine release is TTX-insensitive after probe insertion. Thus, dialysis studies using MFB infusions may have been relatively insensitive in detecting impulse-independent release. It remains unclear what percent of residual extracellular dopamine remains after TTX infusions into either the MFB or striatum, and whether this is due solely to tissue damage or to true impulse independent release. Results using tissue 3-MT accumulation, a noninvasive method, suggest that most dopamine release is impulse flow-dependent. The significance of residual 3-MT accumulation after MFB TTX, however, is also unclear.

A number of issues could confound interpretation of these results. First, TTX infusions might simply alter presynaptic membrane potential in depolarized neurons. If this were the case, TTX might possibly reduce impulse-independent release. Given the mechanism of action of TTX, however, this is unlikely. TTX blocks ion transport in sodium channels which are gated by changes in membrane potential. After opening briefly ( 0.5 to $3.0 \mathrm{msec})$, these channels close by a voltage-independent inactivation process (Armstrong 1981; Sigworth and Neher 1980). TTX does not interfere with voltagesensitive components or the inactivation process (Catterall 1980). In a depolarized neuron with no fluctua- tions in membrane potential, sodium channels should remain closed and TTX should have no effect on this potential. Intracellular recordings of depolarized dopamine neurons have shown steady resting membrane potentials (Grace and Bunney 1986), making changes in axonal membrane potential unlikely. Thus, TTX's effects on 3-MT are most likely mediated by blockade of open sodium channels from impulse flow in nondepolarized neurons.

A second possible confounding issue is that TTX could have diffused into the left striatum, blocking dopamine release mediated by impulse flow from nondopaminergic neurons (e.g., prefrontal glutamatergic neurons). Previous studies of diffusion suggest, however, that this is improbable (Myers 1972). Dye infusions into the MFB performed in the present study showed no dye in the regions of the striatum dissected for biochemical analysis (Figure 1A-F). in Figure 1D, a small region in the most caudal extension of the striatum had some staining. This region, however, was excluded in our dissections (see Methods section). Moreover, TTX infusions that were somewhat more medial and anterior produced markedly lower changes in striatal 3-MT accumulation (data not shown). To look further for evidence of diffusion, we measured hypothalamic 3-MT levels in animals in the chronic haloperidol study. Hypothalamic dopamine innervation comes from intrinsic dopamine neurons (Moore 1987), and hypothalamic dopamine release is partially impulse flow-dependent (Lookingland and Moore 1984; Demarest and Moore 1979). If TTX reduced striatal 3-MT by diffusion, it should also reduce hypothalamic 3-MT. As MFB TTX infusions did not reduce hypothalamic 3-MT levels compared with vehicle infusions, significant diffusion to either the hypothalamus or striatum is unlikely.

A third possible confounding factor is that MFB TTX infusions could have altered glutamate-mediated, impulse-independent dopamine release. Although previous studies have shown this is unlikely to account for reduced release under basal conditions (Keefe et al. 1992), this could be a factor during DI. Glutamate regulation of impulse-independent dopamine release in the striatum and accumbens has been hypothesized to come primarily from the thalamocorticostriatal circuit (Grace 1992; Kilpatrick and Phillipson 1986; Romo et al. 1986). Alterations in either thalamic or cortical activity could influence subcortical dopamine. To test the possibility, TTX was infused into the left thalamus of animals treated with haloperidol for 21 days. Infusion coordinates (Paxinos and Watson 1986) were just above the MFB, $2 \mathrm{~mm}$ dorsal (AP $-2.6 \mathrm{~mm}$, ML $+2.0 \mathrm{~mm}$, and DV $-6.4 \mathrm{~mm}$ relative to bregma) to those used in the previous experiments. Ink infusions showed a diffusion radius similar to those shown in Figures 1A-F, although the center of the diffusion was shifted $2 \mathrm{~mm}$ dorsally. The MFB was not stained, whereas the hippocampus, 
thalamus and cortex were. After chronic haloperidol treatment (similar to the haloperdol chronic $_{\text {/ }}$ haloperidol acute $_{\text {act }}$ group), TTX infusions at these coordinates had no effect on striatal 3-MT on the infused (left) side compared to levels on the noninfused (right) side, whereas infusions using the original coordinates produced a $70 \%$ reduction in left striatal 3-MT ( $n=5$ per group, data not shown). This strongly suggests that TTX infusions exert their effects by altering neurotransmission in the MFB rather than that in the thalamus, hippocampus, or cortex.

A fourth methodologic concern relates to the use of pargyline with 3-MT accumulation. Whereas 3-MT accumulation appears to be a more sensitive index of dopamine release than basal 3-MT (Karoum et al. 1994a,b), it is possible that pargyline could increase synaptic dopamine concentrations high enough to displace haloperidol on $\mathrm{D}_{2}$ receptors and bring cells out of DI. We tested this possibility by measuring basal 3-MT after acute and chronic haloperidol and again after unilateral TTX infusions. Basal 3-MT levels were increased $(30 \%$ to $40 \%$ ) after either acute or chronic haloperidol, but not as high as reported previously with 3-MT accumulation (Egan et al. 1991). Left MFB TTX infusions again produced identical reductions in basal 3-MT in groups treated with acute and chronic haloperidol. Although the magnitude of changes in basal 3-MT were not as great as those seen with 3-MT accumulation, the results clearly demonstrate that pargyline did not qualitatively alter the effects of either acute and chronic haloperidol or the TTX-induced reduction in 3-MT during neuroleptic treatment. Thus, with or without pargyline, data using 3-MT suggest that DI is not associated with an alteration in the amount of dopamine release mediated by the MFB.

A fifth methodologic issue relates to the use of anesthesia. Although DI exists in both anesthetized and unanesthetized animals (Chiodo and Bunney 1985), anesthesia may alter dopamine release (Zhang et al. 1989; Chrapusta et al. 1995). Ketamine was used in this study because it does not appear to alter 3-MT accumulation in the striatum and nucleus accumbens (Chrapusta et al. 1995). A difficulty with using awake, unanesthetized animals is due to the possible stress produced by TTX infusions and resulting hemiplegia. Such stress would likely be different in neuroleptic- versus vehicle-treated animals, confounding interpretation of the results (see Moghaddam and Bunney 1993, for discussion). To study anesthesia effects, we infused TTX into the left MFB of acute and chronically treated rats after chloral hydrate or halothane. Rats anesthetized with halothane were allowed to regain consciousness briefly. With both anesthetics, TTX again markedly reduced striatal 3-MT levels to the same extent in animals treated either acutely or chronically with haloperidol. For example, after chloral hydrate, employed in electrophysiologic studies of DI (Chiodo and Bunney 1983), 3-MT accumulation was reduced on the TTX infused side by $75 \%(0.13 \mathrm{ng} / \mathrm{ml})$ compared to the noninfused side $(0.53 \mathrm{ng} / \mathrm{ml})$. This suggests that the lack of change in impulse-dependent dopamine release during DI is not simply an effect of anesthesia.

A sixth issue is whether 3-MT levels reflect synaptic dopamine under the conditions of this experiment. Numerous studies have shown it to be a reliable index of dopamine release under many other conditions [for review, see Wood and Altar (1988)]. It may be particularly useful for studying release during DI because it does not produce tissue damage associated with dialysis. 3-MT accumulation would not be a reliable index of release when there are alterations in COMT activity or 3-MT clearance (Wood and Altar 1988). Although this possibility has not been excluded, it seems unlikely that MFB TTX infusions would acutely alter either of these parameters.

The results from this study are consistent with neurophysiologic studies of DI, where $22 \%$ to $30 \%$ of dopamine neurons continue to fire during $\mathrm{DI}$, many in a bursting pattern (Chiodo and Bunney 1983; White and Wang 1983). These results are also consistent with a recent report of the effects of MFB TTX perfusions on extracellular dopamine in rats treated chronically with haloperidol (Moghaddam and Bunney 1993). Our results confirm this finding using a noninvasive method and report similar results in the nucleus accumbens. Studies of animals with 6-hydroxydopamine-induced nigrostriatal lesions suggest that compensatory mechanisms (e.g., burst firing) can maintain "normal" levels of extracellular dopamine despite dramatic reductions in dopaminergic innervation. For example, following unilateral 6-hydroxydopamine treatment, rats with $80 \%$ depletion in tissue dopamine have extracellular dialyzable dopamine levels that are no different than controls (Robinson and Whishaw 1988; Zigmond et al. 1989, 1990). When $90 \%$ depletion of tissue dopamine is reached, extracellular dopamine is reduced to about $25 \%$ of control levels. In these animals, acute neuroleptic treatment drives the remaining dopamine neurons into a state of depolarization inactivation. Despite marked reduction in neuronal reserve, however, extracellular dopamine is not reduced further by the induction of DI (Hollerman and Grace 1989; Hollerman et al. 1992). These data support the idea that a relatively small percent of dopamine neurons can maintain relatively high levels of dialyzable dopamine. Similar mechanisms could maintain normal extracellular dopamine levels during DI.

It is unclear what effects neuroleptics and DI might have on abnormal dopamine systems such as those that could exist in psychotic humans. In such cases, hypothesized elevations in dopamine release could return to normal levels with the onset of DI. Alternatively, reduced dopamine levels may not mediate the antipsychotic 
effects of these agents, as originally postulated (Chiodo and Bunney 1983, 1985). DI may act, for example, by altering the reactivity of the system to inputs that are normally activating (e.g., see Keller et al. 1983). Depolarization block produced by chronic neuroleptic treatment, however, does not reduce impulse flow-dependent dopamine release in the striatum or nucleus accumbens in normal, unstressed animals.

In conclusion, TTX infusions into the MFB during chronic neuroleptic treatment reduce 3-MT levels by approximately $70 \%$ in the striatum and $52 \%$ to $59 \%$ in the nucleus accumbens. These results are consistent with studies using GBL to block dopaminergic neuronal impulse flow. Despite DI, dopamine impulse flow continues to regulate amounts of total transmitter release that are not different from those in nondepolarized neurons. Furthermore, dopamine release is not markedly reduced with DI. If DI mediates the antipsychotic effects of neuroleptics, it may do so by either normalizing dopamine levels that could be elevated with psychosis, or by altering the reactivity of the dopamine system to activating stimuli.

\section{ACKNOWLEDGMENTS}

We thank John Commisiong for his valuable assistance with TTX infusions and for his support and encouragement.

\section{REFERENCES}

Armstrong CM (1981): Sodium channels and gating currents. Physiol Rev 66(3):644-683

Altar A, Neve K, Loughlin SE, Marshall JF, Fallon JH (1983): The crossed mesostriatal projection: Neurochemistry and developmental response to lesion. Brain Res 279:1-8

Bettini E, Ceci A, Spinelli R, Samanin R (1987): Neurolepticlike effects of the 1-isomer of fenfluramine on striatal dopamine release in freely moving rats. Biochem Pharmacol 36:2387-2391

Blaha CD, Lane RF (1987): Chronic treatment with classical and atypical antipsychotic drugs differentially decreases dopamine release in striatum and nucleus accumbens in vivo. Neurosci Lett 78:199-204

Brown EE, Damsma G, Cumming P, Fibiger HC (1991): Interstitial 3-methoxytyramine reflects striatal dopamine release: An in vivo microdialysis study. J Neurochem 57(2):701-707

Bunney BS, Grace AA (1978): Acute and chronic haloperdiol treatment: Comparison of effects on nigral dopaminergic cell activity. Life Sci 23:1715-1728

Butcher SP, Fairbrother IS, Kelly JS, Arbuthnott (1990): Effects of selective monoamine oxidase inhibitors on the in vivo release and metabolism of dopamine in the rat striatum. J Neurochem 55(3):981-988

Catterall WA (1980): Neurotoxins that act on voltage-sensitive sodium channels in excitable membranes. Ann Rev Pharmacol Toxicol 20:15-43
Carr VJ (1983): Recovery from schizophrenia: A review of patterns of psychosis. Schizophr Bull 9:95-121.

Cenci MA, Kalen P, Mandel RJ, Bjorklund A (1992): Regional differences in the regulation of dopamine and noradrenaline release in medial frontal cortex, nucleus accumbens and caudate-putamen: A microdialysis study in the rat. Brain Res 581:217-228.

Chen J, Paredes W, Gardner EL (1991): Chronic treatment with clozapine selectively decreases basal dopamine release in nucleus accumbens but not in caudate-putamen as measured by in vivo microdialysis: Further evidence for depolarization block. Neurosci Lett 122:127-131

Chiodo LA, BS Bunney (1983): Typical and atypical neuroleptics: Differential effects of chronic administration on the activity of A-9 and A-10 midbrain dopaminergic neurons. J Neurosci 3:1607-1619

Chiodo LA, Bunney BS (1985): Possible mechanisms by which repeated clozapine administration differentially affects the activity of two subpopulations of midbrain dopamine neurons. J Neurosci 5:2538-2544

Chiodo LA, Bunney BS (1987): Population response of midbrain dopaminegic neurons to neuroleptics: Further studies on time course and nondopaminergic neuronal influences. J Neurosci 7:629-633

Chrapusta SJ, Karoum F, Egan MF, Wyatt RJ (1994): Evidence for impulse flow-independent dopamine release, and their relationship to dopamine metabolism in three rat brain regions. Eur J Pharmacol 655:271-275

Chrapusta SJ, Egan MF, Karoum F, Wyatt RJ (1995): Regional effects of general anesthetics on dopamine release in rat brain: A 3-methoxytyramine study. Brain Res (in press)

Commisiong JW, Slimovitch C, Toffano G. (1990): Regulation of the synthesis and metabolism of striatal dopamine after disruption of nerve conduction in the medial forebrain bundle. Br J Pharmacol 99:741-749

Compton DR, Johnson KM (1989): Effects of acute and chronic clozapine and haloperidol on in vitro release of acetylcholine and dopamine from striatum and nucleus accuumbens. J Pharmacol Exp Ther 248:521-536

Creese I, Burt DR, Snyder SH (1976): Dopamine receptor binding predicts clinical and pharmacologic potencies of antischizophrenic drugs. Science 192:481-483

Demarest KT and Moore KE (1979): Comparison of dopamine synthesis regulation in the terminals of nigrostriatal, mesolimbic, tuberoinfundibular, and tuberohypophyseal neurons. J Neural Transm 46:263-277

Egan MF, Karoum F, Wyatt RJ (1991): Effects of acute and chronic clozapine and haloperidol administration on 3-methoxytyramine accumulation in rat prefrontal cortex, nucleus accumbens, and striatum. Eur J Pharmacol 199:191-199

Egan MF, Chrapusta SJ, Karoum FK, Wyatt RJ (1993): Evidence against the depolarization block hypothesis of the mechanism of action of antipsychotic drugs: Effects of tetrodotoxin infusion into the median forebrain bundle after acute and chronic dopamine release. Schizophr Res 9:218

Glovinsky D, Kirch DG, Wyatt RJ (1992): Early antipsychotic response to resumption of neuroleptics in drug-free chronic schizophrenic patients. Biol Psychiatry 31:968-970

Grace AA (1991): Plastic versus tonic dopamine release and 
the modulation of dopamine system responsivity: A hypothesis for the etiology of schizophremia. Neuroscience 41(1):1-24

Grace AA (1992): The depolarization block hypothesis of neuroleptic action: Implications for the etiology and treatment of schizophrenia. J Neural Transm 36(suppl):91-131

Grace AA, Bunney BS (1986): Induction of depolarization block in midbrain dopaminergic neurons by repeated admimistration of haloperidol: Analysis using in vivo intracellular recording. J Pharmacol Exp Therap 238: 1092-1100

Gonon FG (1988): Nonlinear relationship between impulse flow and dopamine released by rat midbrain dopaminergic neurons as studied by in vivo electrochemistry. Neuroscience 24(1):19-28

Hernandez L, Hoebel B (1989): Haloperidol given chronically decreases basal dopamine in the prefrontal cortex more than the striatum or nucleus accumbens as simultaneously measured by microdialysis. Brain Res Bull 22:763-769

Hollerman JR, Grace AA (1989): Acute haloperidol administration induces depolarization block of nigral dopamine neurons in rats after partial dopamine lesions. Neurosci Lett 96:82-88

Hollerman JR, Abercrombie ED, Grace AA (1992): Electrophysiologic, biochemical, and behavioral studies of acute and haloperidol-induced depolarization block of nigral dopamine neurons. Neuroscience 47(3):589-601

Ichikawa J, Meltzer HY (1990): The effect of chronic clozapine and haloperidol on basal dopamine release and metabolism in rat striatum and nucleus accumbens studied by in vivo microdialysis. Eur J Pharmacol 176:371-374

Imperato A, DiChiarra G (1985): Dopamine release and metabolism in awake rats as studied by transstriatal dialysis. J Neurosci 5:297-306

Invernizzi R, Morali F, Possi L, Samanin R (1990): Effects of acute and chronic clozapine on dopamine release and metabolism in the striatum and nucleus accumbens of conscious rats. $\mathrm{Br}$ J Pharmacol 99:741-749

Kalivas PW and Duffy P (1991): A comparison of axonal and somatodendritic dopamine release using in vivo dialysis. J Neurochem 56:961-967

Karoum F, Egan MF (1992): Dopamine release and metabolism in the rat frontal cortex, nucleus accumbens, and striatum: A comparison of acute clozapine and haloperidol. Br J Pharmacol 105:703-707

Karoum F, Chrapusta SJ, Egan MF (1994a): 3-Methoxytyramine is the major metabolite of released dopamine in the rat frontal cortex: Reassessment of the effects of antipsychotics on the dynamics of dopamine release and metabolism in the frontal cortex, nucleus accumbens, and striatum by a simple two-pool model. J Neurochem 63(3):972-979

Karoum F, Chrapusta SJ, Brinjak R, Hitri A, Wyatt RJ (1994b): Regional effects of amphetamine, cocaine, nomifensine, and GBR 12909 on the dynamics of dopamine release and metabolism in the rat brain. Br J Pharmacol 113: 1391-1399

Keck PE, Cohen BM, Baldessarini RJ, McElroy SL (1989): Time course of antipsychotic effects of neuroleptic drugs. Am J Psychiatry 146:1289-1292
Keefe KA, Zigmond MJ, Abercrombie ED (1992): Extracellular dopamine in striatum: Influence of nerve impulse activity in medial forebrain bundle and local glutamatergic input. Neuroscience 47:325-332

Keefe KA, Sved AF, Zigmond MJ, Abercrombie ED (1993): Stress-induced dopamine release in the neostriatum: Evaluation of the role of action potentials in nigrostriatal dopamine neurons or local infiltration by endogenous excitatory amino acids. J Neurochem 61:1943-1952

Keller RW, Stricker EM, Zigmond MJ (1983): Environmental stimuli but not homeostatic challenges produce apparent increases in dopaminergic activity in the striatum: An analysis by in vivo voltammentry. Brain Res 279: 159-170

Kuczenski R, Segal DS (1992): Differential effects of amphetamine and dopamine uptake blockers (cocaine, nomifensine) on caudate and accumbens dialysate dopamine and 3-methoxytyramine. J Pharmacol Exp Ther 262: 1085-1094

Lane RF, Blaha CD (1987): Chronic haloperidol decreases dopamine release in striatum and nucleus accumbens in vivo: Depolarization block as a possible mechanism of action. Brain Res Bull 18:135-142

Lookingland KJ, Moore KE (1984): Dopamine receptor-mediated regulation of incertohypothalamic dopaminergic neurons in the male rat. Brain Res 304:329-338

Loughlin SE, Fallon JH (1982): Mesostriatal projections from ventral tegmentum and dorsal raphe: Cells project ipsilaterally or contralaterally but not bilaterally. Neurosci Lett 32:11-16

Meyers RD (1972): Methods for chemical stimulation of the brain. In Meyers RD (ed), Methods in Psychobiology. New York, Academic Press, pp 247-279

Moghaddam B, Bunney BS (1993): Depolarization inactivation of dopamine neurons: Terminal release characteristics. Synapse 14:195-200

Moore KE (1987): Hypothalamic dopaminergic neuronal systems. In Meltzer HY (ed), Psychopharmacology: The Third Generation of Progress. New York, Raven Press, pp 127-139

Miu P, Karoum F, Toffano G, Commisiong JW (1992): Regulatory aspects of nigrostriatal dopamine neurons. Exp Brain Res 91:489-495

Narahashi T (1974): Chemicals as tools in the study of excitable membranes. Physiol Rev 54(4):813-877

Osborne PG, O'Connor WT, Drew KL, Ungerstedt U (1990): An in vivo microdialysis characterization of extracellular dopamine and GABA in dorsolateral striatum of awake freely moving and halothane anesthetized rats. J Neurosci Methods 34:99-105

Paxinos G, Watson C (1986): The Rat Brain in Stereotaxic Coordinates, 2nd ed. New York, Academic Press.

Robinson TE, Whishaw IQ (1988): Normalization of extracellular dopamine in striatum following recovery from a partial unilateral 6-OHDA lesions of the substantia nigra: A microdialysis study in freely moving rats. Brain Res 450:209-224

Romo R, Cheramy A, Godeheu G, Glowinski J (1986): In vivo presynaptic control of dopamine release in the cat cau- 
date nucleus-I. Opposite changes in neuronal activity and release evoked from thalamic motor nuclei. Neuroscience 19:1067-1079

Schmidt CJ, Sullivan CK, Fadayel GM (1994): Blockade of striatal 5-hydroxytryptamine ${ }_{2}$ receptors reduces the increase in extracellular concentrations of dopamine produced by the amphetamine analogue 3,4-methylenedioxymethamphetamine. J Neurochem 62:1382-1389

See RE, Chapman MA, Meshul CK (1992): Comparison of chronic intermittent haloperidol and raclopride effects on striatal dopamine release and synaptic ultrastructure in rats. Synapse 12:147-154

Sigworth FJ, Neher E (1980): Single $\mathrm{Na}^{+}$channel currents observed in cultured rat muscle cells. Nature 287:447-449

Skarsfeldt T (1988): Differential effects after repeated treatment with haloperidol, clozapine, thioridazine, and tefludazine on SNC and VTA dopamine neurones in rats. Life Sci 42:1037-1044

Stern RG, Kahn RS, Harvey PD, Amin F, Apter SH, Hirschowitz J (1993): Early response to haloperidol treatment in chronic schizophrenia. Schizophr Res 10(2):165-171

Tanaka T, Vincent SR, Nomikos GG, Fibiger HC (1992): Effect of quinine on autoreceptor-regulated dopamine release in the rat striatum. J Neurochem 59:1640-1645

Tepper JM, Creese I, Schwartz DH (1991): Stimulus-evoked changes in neostriatal dopamine levels in awake and anesthetized rats as measured by microdialysis. Brain Res 534:283-292

Westerink BHC, De Vries JB (1988): Characterization of in vivo dopamine release as determined by brian microdialysis after acute and subchronic implantations: Methodologic aspects. J Neurochem 51:683-687

White FJ, Wang RX (1983a): Comparison of the effects of chronic haloperidol treatment on A-9 and A-10 dopaminergic neurons in the rat. Life Sci 32:983-993

White FJ, Wang RX (1983b): Differential effects of classical and atypical antipsychotic drugs on A9 and A10 dopamine neurons. Science 221:1054-1057

Wood PL, Kim HS, Marien MR (1987): Intracerebral dialysis: Direct evidence for the utility of 3-MT measurements as an index of dopamine release. Life Sci 41:1-9

Wood PL, Altar CA (1988): Dopamine release in vivo from nigrostriatal mesolimbic and mesocortical neurons: Utility of 3-methoxytyramine measurements. Pharmacol Rev 4:163-187

Wood PL, Kim HS, Stocklin K, Rao TS (1988): Dynamics of the striatal 3-MT pool in rat and mouse: Species differences as assessed by steady-state measurements and intracerebral dialysis. Life Sci 42:2275-2281

Zetterstrom T, Sharp T, Ungerstedt U (1985): Effect of neuroleptic drug on striatal dopamine release and metabolism in the awake rat studied by intracerebral dialysis. Eur J Pharmacol 106:27-37

Zhang W, Tilson H, Stachowiak MK, Hong JS (1989): Repeated haloperidol changes basal release of striatal dopamine and subsequent response to haloperidol challenge. Brain Res 484:389-392

Zigmond MJ, Berger TW, Grace AA, Stricker EM (1989): Compensatory responses to nigrostriatal bundle injury: Studies with 6-hydroxydopamine in an animal model of Parkinson. Mol Chem Neuropathol 10:185-200

Zigmond MJ, Abercrombie ED, Berger TW, Grace AA, Stricker EM (1990): Compensation after lesions of central dopaminergic neurons. Some clinical and basic implications. TINS 13(7):290-295 